\title{
EFFECT OF TRAPPED PARTICLES IN THE BEAT OF TWO WAVES ON THE
} WAVE DYNAMICS

Krlin L.: Czech. J. Phys. B 31 (1981) 383

References to equations $(56-58)$ :

Pátek J.: Diploma Thesis, Charles University, Prague, 1975.

Krlin L., Pátek J.: Preprint IPPCZ-212 of the Institute of Plasma Physics, Czechosl. Acad. Sci., Prague, 1977.

See also canonical perturbation approach in: Johnston S., Kaufman A. N.: J. Plasma Phys. 22 (1979) 105. 